\title{
First-year results of the Global Influenza Hospital Surveillance Network: 2012-2013 Northern hemisphere influenza season
}

Joan Puig-Barberà ${ }^{*}$, Anita Tormos ${ }^{1}$, Anna Sominina², Elena Burtseva ${ }^{3}$, Odile Launay ${ }^{4,5}$, Meral A Ciblak Angels Natividad-Sancho ${ }^{1}$, Amparo Buigues-Vila', Sergio Martínez-Úbeda' ${ }^{1}$ Cedric Mahé ${ }^{7}$ and on behalf of The GIHSN Group

\begin{abstract}
Background: The Global Influenza Hospital Surveillance Network (GIHSN) was developed to improve understanding of severe influenza infection, as represented by hospitalized cases. The GIHSN is composed of coordinating sites, mainly affiliated with health authorities, each of which supervises and compiles data from one to seven hospitals. This report describes the distribution of influenza viruses $\mathrm{A}(\mathrm{H} 1 \mathrm{~N} 1), \mathrm{A}(\mathrm{H} 3 \mathrm{~N} 2)$, BNictoria, and B/Yamagata resulting in hospitalization during 2012-2013, the network's first year.

Methods: In 2012-2013, the GIHSN included 21 hospitals (five in Spain, five in France, four in the Russian Federation, and seven in Turkey). All hospitals used a reference protocol and core questionnaire to collect data, and data were consolidated at five coordinating sites. Influenza infection was confirmed by reverse-transcription polymerase chain reaction. Hospitalized patients admitted within 7 days of onset of influenza-like illness were included in the analysis.
\end{abstract}

Results: Of 5034 patients included with polymerase chain reaction results, 1545 (30.7\%) were positive for influenza. Influenza $\mathrm{A}(\mathrm{H} 1 \mathrm{~N} 1), \mathrm{A}(\mathrm{H} 3 \mathrm{~N} 2)$, and both $\mathrm{B}$ lineages co-circulated, although distributions varied greatly between coordinating sites and over time. All age groups were affected. $\mathrm{A}(\mathrm{H} 1 \mathrm{~N} 1)$ was the most common influenza strain isolated among hospitalized adults 18-64 years of age at four of five coordinating sites, whereas $A(H 3 N 2)$ and $B$ viruses were isolated more often than $\mathrm{A}(\mathrm{H} 1 \mathrm{~N} 1)$ in adults $\geq 65$ years of age at all five coordinating sites. A total of 16 deaths and 20 intensive care unit admissions were recorded among patients with influenza.

Conclusions: Influenza strains resulting in hospitalization varied greatly between coordinating sites and over time. These first-year results of the GIHSN are relevant, useful, and timely. Due to its broad regional representativeness and sustainable framework, this growing network should contribute substantially to understanding the epidemiology of influenza, particularly for more severe disease.

Keywords: Influenza epidemiology, Surveillance network, Hospital

\footnotetext{
*Correspondence: puig_joa@gva.es

${ }^{1}$ Fundación para el Fomento de la Investigación Sanitaria y Biomédica de la

Comunidad Valenciana (FISABIO-Salud Pública), Valencia, Spain

Full list of author information is available at the end of the article
} 


\section{Background}

According to the World Health Organization (WHO), seasonal influenza epidemics affect an estimated 5-15\% of the total population worldwide, with 3-5 million cases of severe illness, resulting in 250,000-500,000 deaths [1]. However, few data are available for many parts of the world where active surveillance is lacking. In addition, the viruses and the severity of influenza epidemics vary greatly between years and geographical areas [2-4]. To address the rapidly evolving antigenicity of circulating influenza viruses, twice annually, the WHO re-evaluates the viruses that should be included in the seasonal influenza vaccines. To inform policy decisions, national health authorities need to understand the burden of influenza disease and the impact of current vaccination programs in their countries.

High-quality, active surveillance networks are needed to better understand influenza epidemiology and therefore better control influenza epidemics [5-7]. Data from existing sentinel physician networks are used in several countries to conduct annual studies on the effectiveness of vaccines in preventing medically attended influenzalike illness (ILI) [8-12]. These networks, however, do not collect data on the impact of influenza infection on hospitalization or on the impact of influenza vaccines on influenza-related hospitalization, which substantially influence evaluation of the benefits and cost-effectiveness of influenza vaccines [13].

Active surveillance networks are also powerful advocacy instruments for highlighting the often-underestimated impact of influenza [5]. While hospital surveillance systems already exist for detecting outbreaks of respiratory viruses [14-16], few focus on the actual burden of serious influenza cases using the specific outcome of laboratoryconfirmed influenza; instead, the burden is most often estimated from hospital databases using criteria prone to various biases [13,17].

The Global Influenza Hospital Surveillance Network (GIHSN) was initiated in 2011 to fill this gap in epidemiology and public health knowledge. The GIHSN is a public-private partnership between Sanofi Pasteur, FISABIO-Salud Pública, and several coordinating sites affiliated with national health authorities. In accordance with WHO recommendations [7], coordinating sites are selected based on their motivation, geographic representativeness, ability to conduct epidemiological studies, availability of laboratory facilities, and experience in influenza surveillance. Each coordinating site supervises a group of one to seven hospitals in its country or geographical region and follows a core reference protocol. The GIHSN has three main objectives: (i) evaluate the burden of severe influenza disease, defined as hospitalization related to community-acquired influenza or complications following an influenza infection; (ii) quantify the distribution of the different influenza viruses $(\mathrm{A}(\mathrm{H} 1 \mathrm{~N} 1)$, A
(H3N2), B/Yamagata, and B/Victoria) among these severe cases; and (iii) measure the effectiveness of influenza seasonal vaccines to prevent these hospitalizations using a test-negative design.

In this report, we evaluated the characteristics of hospitalizations related to influenza and the temporal and geographic distribution of the different influenza viruses in these cases during the 2012-2013 Northern hemisphere influenza season, the program's first year.

\section{Methods}

\section{Study design}

This was a multi-centre, prospective, active surveillance, hospital-based epidemiological study during the 20122013 influenza season in 21 hospitals in Spain, France, Turkey, and the Russian Federation (Table 1). Data on hospitalized patients with a diagnosis possibly associated with influenza were collected by an active surveillance system composed of healthcare professionals trained to follow a common reference protocol. Data were consolidated at five coordinating sites, including one in Spain (Valencia), one in France, one in Turkey, and two in the Russian Federation (Moscow and St. Petersburg).

The reference protocol was adapted by the coordinating sites according to their local conditions. In particular, case identification was adapted to the specific local setting because of the differences in health care delivery systems between the different countries and differences in the types of hospitals included, although admission diagnosis codes for inclusion were the same for all sites. At each site, except Turkey, the study start was predefined according to the site experience of the influenza epidemic wave [8]. No study period was defined for Turkey because it was included as a pilot study. Specificities between coordinating sites in the application of the reference protocol are summarized in Table 2.

The GISHN study was approved by the local research ethics committees for each institution: Comité Ético de la Dirección General de Salud Pública y Centro Superior de Investigación en Salud Pública (CEIC-DGSP-CSISP), Spain; Comité de Protection des Personnes Ile-de-France III, France; Ethic Committee of Hospital \#1 for Infectious Diseases of Moscow Health Department, the Russian Federation; Ethics Committee of the Research Institute of Influenza, St. Petersburg, the Russian Federation; Istanbul University, Istanbul Faculty of Medicine, Ethical Committee for Clinical Research, Turkey. All subjects included in the study or their legal representatives provided written informed consent following local research ethics boards' requirements.

\section{Study population}

Non-institutionalized patients hospitalized for at least $24 \mathrm{~h}$ with a diagnosis possibly associated with influenza 
Table 1 Hospital characteristics

\begin{tabular}{|c|c|c|c|c|c|c|c|}
\hline Country & $\begin{array}{c}\text { Participating } \\
\text { hospital }\end{array}$ & Type of Hospital & $\begin{array}{l}\text { Total no. } \\
\text { of beds }\end{array}$ & $\begin{array}{l}\text { No. of beds for } \\
\text { general medicine }\end{array}$ & $\begin{array}{l}\text { No. of beds for } \\
\text { paediatrics }\end{array}$ & $\begin{array}{c}\text { No. of beds for } \\
\text { geriatrics }\end{array}$ & $\begin{array}{c}\text { No. of ICU } \\
\text { beds }\end{array}$ \\
\hline \multicolumn{8}{|l|}{ Spain } \\
\hline & General CS & General & 580 & 437 & 79 & 0 & 58 \\
\hline & La Plana & General & 251 & 100 & 19 & 0 & 9 \\
\hline & Pesset & General & 540 & 211 & 41 & 0 & 16 \\
\hline & San Juan & General & 350 & 230 & 37 & 0 & 13 \\
\hline & Elda & General & 514 & 410 & 30 & 0 & 13 \\
\hline \multicolumn{8}{|l|}{ France } \\
\hline & Cochin & - & 1074 & - & - & - & - \\
\hline & Bichat & University hospital & 1000 & 954 & 0 & 20 & 24 \\
\hline & Limoges & - & 858 & - & - & - & - \\
\hline & Montpellier & - & 3000 & - & - & - & - \\
\hline & Lyon & $\begin{array}{l}\text { University hospital/ } \\
\text { tertiary care }\end{array}$ & 683 & 603 & 0 & 64 & 53 \\
\hline \multicolumn{8}{|l|}{ Moscow } \\
\hline & Hospital \#1 & Infectious diseases & 1000 & 506 & 231 & 0 & 12 \\
\hline \multirow{4}{*}{$\begin{array}{l}\text { St. } \\
\text { Petersburg }\end{array}$} & & & & & & & \\
\hline & Hospital \#30 & Infectious diseases & 1200 & 1175 & 0 & - & 25 \\
\hline & Hospital \#5 & $\begin{array}{c}\text { Children's infectious } \\
\text { diseases }\end{array}$ & 650 & 0 & 635 & 0 & 15 \\
\hline & Hospital \#4 & Children's city hospital & 360 & 0 & 345 & 0 & 15 \\
\hline \multicolumn{8}{|l|}{ Turkey } \\
\hline & Hacettepe Univ. Hospital & - & 1200 & 156 & 228 & - & 60 \\
\hline & Gazi Univ. Hospital & - & 1150 & - & - & - & - \\
\hline & Trakya Univ. Hospital & University hospital & 1042 & 951 & 72 & 0 & 50 \\
\hline & $\begin{array}{c}\text { Istanbul Univ. Cerrahpaşa } \\
\text { Hospital }\end{array}$ & University hospital & - & 36 & 60 & 0 & 30 \\
\hline & Uludağ Univ. Hospital & - & 1000 & 800 & 112 & 0 & 87 \\
\hline & Dr. Siyami Ersek Hospital & - & - & - & - & - & - \\
\hline & Kartal Research Hospital & $\begin{array}{c}\text { Research and education } \\
\text { Hospital }\end{array}$ & 880 & 750 & 90 & 0 & 41 \\
\hline
\end{tabular}

Dashes indicate missing information. No., number. ICU, intensive care unit.

were considered eligible to be included in the study (see Additional file 1: Table S1 for admission diagnosis codes). Patients in the Russian Federation, Spain, and Turkey could be of any age, whereas in France, only patients $\geq 18$ years of age were screened.

Subjects $\geq 5$ years of age had to meet the European Centre for Disease Prevention and Control's clinical case definition of influenza-like-illness (ILI) [18], which included at least one of four systemic symptoms (fever or feverishness, headache, myalgia, or malaise) and at least one of three respiratory symptoms (cough, sore throat or shortness of breath), although we did not include sudden onset of symptoms as a criterion. Subjects $\geq 5$ years of age also had to have been hospitalized within 7 days of the onset of ILI. Children $<5$ years of age had to have been admitted to the hospital within 7 days of the appearance of symptoms potentially associated with influenza. Patients were excluded if they had been discharged from a hospital within 30 days of the current admission.

\section{Data and sample collection}

A nasopharyngeal swab was obtained from all patients. An additional pharyngeal swab was collected for patients $\geq 14$ years of age and a nasal sample for children $<14$ years old. Samples were collected within $48 \mathrm{~h}$ of hospital admission and were stored at $-20^{\circ} \mathrm{C}$ at the study site or were sent directly to the coordinating site's laboratory for testing. Influenza infection status, patient demographics, and influenza vaccination status were recorded with a core questionnaire via a combination of face-to-face interview of patients or legal representatives, interviews of attending physicians, and a review of clinical records. 
Table 2 Protocol specificities between coordinating sites

\begin{tabular}{|c|c|c|c|c|c|}
\hline Characteristic & Valencia, Spain & St. Petersburg, Russia & Moscow, Russia & Turkey & France \\
\hline Hospitals & $\begin{array}{c}5 \text { health care district general } \\
\text { hospitals }\end{array}$ & $\begin{array}{l}1 \text { infectious disease hospital, } 1 \text { children's city } \\
\text { hospital, } 1 \text { children's infectious disease hospital }\end{array}$ & 1 infectious disease hospital & 7 general hospitals & 5 university hospitals \\
\hline Screening ward & Emergency & Emergency and 3 selected wards & Paediatric, mixed, pregnancy, adults & $\begin{array}{l}\text { Emergency and } 7 \\
\text { selected wards }\end{array}$ & $\begin{array}{l}\text { Emergency and }>20 \\
\text { selected wards }\end{array}$ \\
\hline Screening diagnosis & $\begin{array}{c}\text { Admission diagnosis associated } \\
\text { with influenza infection; clinical } \\
\text { symptoms of ILI }\end{array}$ & Clinical symptoms of ILI & $\begin{array}{c}\text { Admission diagnosis associated } \\
\text { with influenza inflection; } \\
\text { clinical symptoms } \\
\text { of ILI }\end{array}$ & $\begin{array}{l}\text { Clinical symptoms } \\
\text { of ILI }\end{array}$ & $\begin{array}{l}\text { Signs of respiratory } \\
\text { illness for }<7 \text { days }\end{array}$ \\
\hline Recruited by & Full-time trained nurses & Doctors & Doctors, nurses, heads of wards & Doctors & $\begin{array}{l}\text { Doctors, clinical } \\
\text { researchers, nurses }\end{array}$ \\
\hline $\begin{array}{l}\text { Additional exclusion } \\
\text { criteria }\end{array}$ & Outside catchment area & - & - & - & $\begin{array}{l}\text { Not affiliated with social } \\
\text { security }\end{array}$ \\
\hline Study start criteria & $\begin{array}{l}2 \text { consecutive weeks } \\
\text { with } \geq 2 \text { cases }\end{array}$ & $\begin{array}{c}\text { Week with } \geq 5 \text { laboratory-confirmed influenza cases } \\
\text { using national surveillance data }\end{array}$ & $\begin{array}{c}\text { Week with } \geq 5 \text { laboratory-confirmed } \\
\text { influenza cases using national } \\
\text { surveillance data }\end{array}$ & Not defined ${ }^{a}$ & $\begin{array}{l}\text { Defined by the national } \\
\text { surveillance system }\end{array}$ \\
\hline Study end criteria & $\begin{array}{l}2 \text { consecutive weeks } \\
\text { with no cases }\end{array}$ & Week with no laboratory-confirmed influenza cases & $\begin{array}{l}\text { Week with no laboratory-confirmed } \\
\text { influenza cases }\end{array}$ & Not defined ${ }^{a}$ & $\begin{array}{l}\text { Defined by the national } \\
\text { surveillance system }\end{array}$ \\
\hline $\begin{array}{l}\text { Actual study period } \\
\text { (epidemiological weeks) }\end{array}$ & $2013-01-2013-15$ & $2013-03-2013-22$ & $2013-02-2013-21$ & $2013-01-2013-14$ & $2012-51-2013-16$ \\
\hline
\end{tabular}

${ }^{\mathrm{a} S t u d y}$ period not defined because it was a pilot study. Cases of ILI were reported between epidemiological weeks 1 and 14 of 2013.

Dashes indicate no additional exclusion criteria. 
Whenever possible, information about vaccination status collected with the core questionnaire was validated by existing registers or vaccination cards or by contacting the place where patients were administered the vaccine. A patient was considered as having received the current season's influenza vaccination if their records demonstrated or if they recalled receiving it $>14$ days before the onset of ILI.

\section{Confirmation of influenza infection}

RNA extraction and multiplex reverse transcriptasepolymerase chain reaction (RT-PCR) were performed at the coordinating sites to detect influenza A (H3N2), A (H1N1)pdm09, B/Yamagata, and B/Victoria according to local laboratory procedures. Coordinating sites in France, the Russian Federation, and Turkey are WHO National Influenza Centres, and the coordinating site in Valencia, Spain used the WHO RT-PCR protocol. Details of the RTPCR methods are provided in the Additional file 2: Supplemental methods.

\section{Data management and statistical analysis}

Coordinating sites collected anonymized data from the core questionnaires and checked for missing, inconsistent, or incorrect data. Whenever possible, queries of any inconsistencies or missing data were resolved by the investigators at each of the coordinating sites. Missing data were not replaced for the statistical analyses. Data from each coordinating site were shared with the network coordinating centre (FISABIO-Salud Pública, Valencia, Spain) via a secured, internet-based system.
Only samples taken within 7 days of symptom onset were included in the analysis. Descriptive statistics were calculated for the characteristics of influenza-associated hospitalization by age group, influenza virus and sociodemographic characteristics.

Statistical analysis and data management was performed using STATA version 12 (StataCorp, College Station, TX).

\section{Results}

A total of 8795 patients hospitalized for diagnoses possibly related to influenza were considered eligible for this study (Table 3). Informed consent was obtained from 8162 (92.8\%), who were subsequently screened for inclusion. A total of 5034 patients with valid RT-PCR results were included and, of these, 1545 (30.7\%) were positive for influenza. Overall, the largest contributors of influenzapositive samples were St. Petersburg $(n=652 ; 42.2 \%)$ and Moscow $(\mathrm{n}=471 ; 30.5 \%)$, followed by Spain $(\mathrm{n}=236$; $15.3 \%)$ and France $(\mathrm{n}=150 ; 9.7 \%)$. Turkey, included as a pilot study, accounted for $2.3 \%(n=36)$ of the laboratoryconfirmed influenza cases. Hospitalization with confirmed influenza was recorded for $15.7 \%$ of the included subjects for Spain, 33.8\% for Moscow, 39.6\% for St. Petersburg, $34.7 \%$ for France, and $65.5 \%$ for Turkey.

\section{Epidemiology of hospitalization with laboratory- confirmed influenza}

Cases hospitalized with confirmed influenza peaked between the fourth and eighth epidemiological week of 2013 (Figure 1). The timing of suspected influenza cases

Table 3 Patient disposition, samples processed, and number of admissions with laboratory-confirmed influenza by coordinating site

\begin{tabular}{|c|c|c|c|c|c|c|}
\hline Characteristic & $\begin{array}{l}\text { Valencia, } \\
\text { Spain }\end{array}$ & $\begin{array}{l}\text { St. Petersburg, } \\
\text { Russia }\end{array}$ & $\begin{array}{l}\text { Moscow, } \\
\text { Russia }\end{array}$ & Turkey & France & Overall \\
\hline Records received, $\mathrm{n}$ & 5038 & 1986 & 1677 & 67 & 447 & 9215 \\
\hline Institutionalized, n & 329 & 7 & 21 & 0 & 0 & 357 \\
\hline Non-resident ${ }^{\mathrm{a}}, \mathrm{n}$ & 63 & - & - & - & - & 63 \\
\hline Eligible, $n$ & 4646 & 1979 & 1656 & 67 & 447 & 8795 \\
\hline Unable to communicate with patient or proxy, $\mathrm{n}$ & 250 & 47 & 2 & 1 & 0 & 300 \\
\hline Consent not given, $\mathrm{n}$ & 156 & 166 & 11 & 0 & 0 & 333 \\
\hline Screened for inclusion, $\mathrm{n}$ & 4240 & 1766 & 1643 & 66 & 447 & 8162 \\
\hline Did not meet inclusion/exclusion criteria, $\mathrm{n}$ & 1872 & 106 & 128 & 11 & 12 & 2129 \\
\hline Swab not taken, n & 5 & 7 & 115 & 0 & 0 & 127 \\
\hline Eligible and tested, $\mathrm{n}$ & 2363 & 1653 & 1400 & 55 & 435 & 5906 \\
\hline RT-PCR results missing or invalid, $n$ & 67 & 2 & 8 & 0 & 2 & 79 \\
\hline Samples processed with RT-PCR results, $n$ & 2296 & 1651 & 1392 & 55 & 433 & 5827 \\
\hline Sample taken outside the defined influenza season, $\mathrm{n}$ & 789 & 3 & 0 & 0 & 1 & 793 \\
\hline Samples with valid RT-PCR results, $n$ & 1507 & 1648 & 1392 & 55 & 432 & 5034 \\
\hline Influenza-positive, n (\%) & $236(15.7)$ & $652(39.6)$ & $471(33.8)$ & $36(65.5)$ & $150(34.7)$ & $1545(30.7)$ \\
\hline
\end{tabular}

Dashes indicate category not applicable.

${ }^{\mathrm{a}}$ Spain only. 


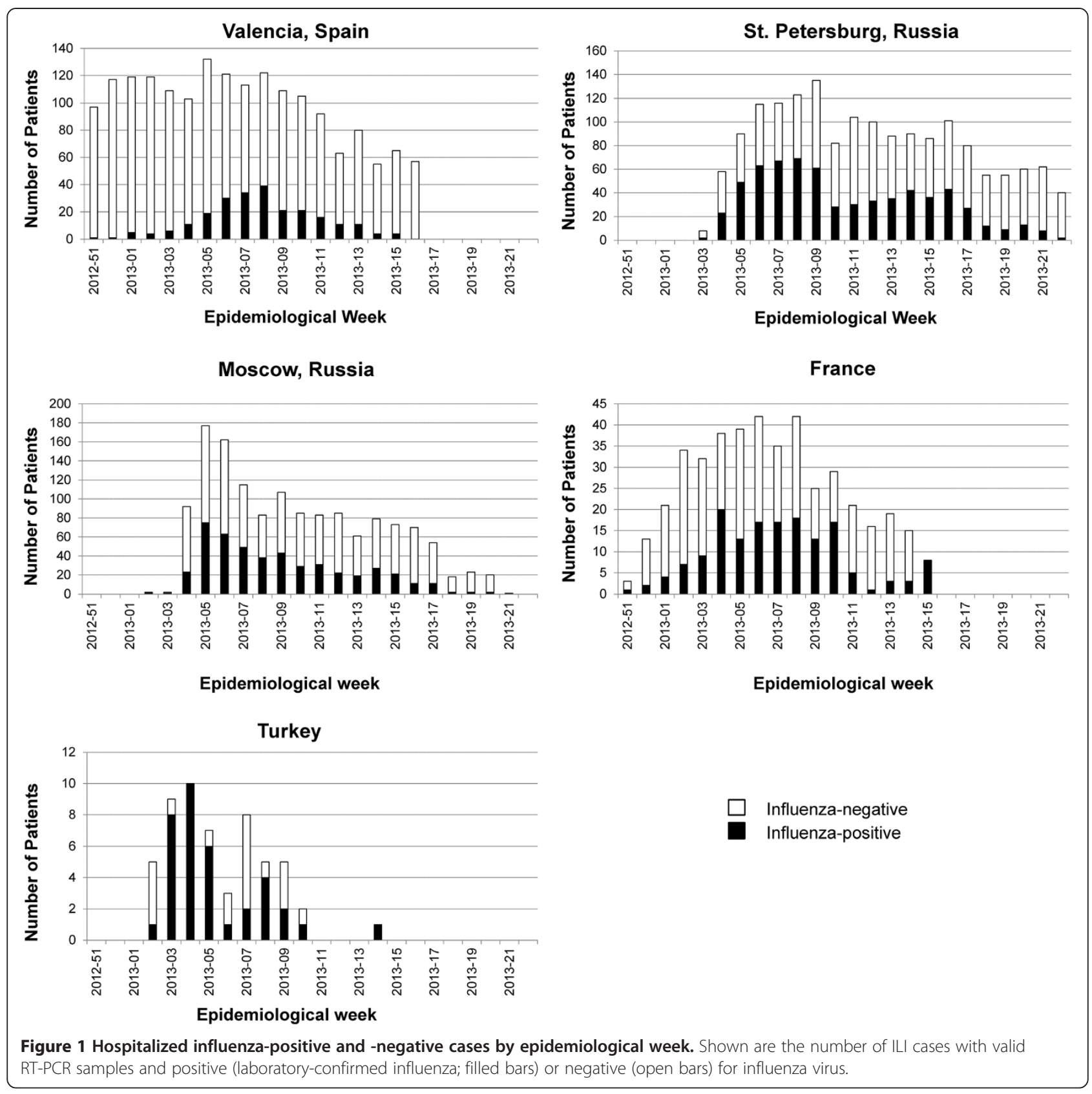

generally paralleled that of confirmed cases except in Spain, where the number remained elevated for the duration of the study because of the boarder criteria for case identification. For all countries, the influenza season, as defined by the appearance of confirmed influenza cases, started around the beginning of 2013 (epidemiological week 51 of 2012 to week 3 of 2013) and lasted until epidemiological week 14 to 22 of 2013. The influenza season was similar in Moscow and St. Petersburg, although in St. Petersburg, influenza cases remained elevated over a longer period with no clear peak. In Spain and France, reporting of influenza cases began and ended earlier.
All four influenza viruses examined in this study (A (H1N1), A(H3N2), B/Yamagata, and B/Victoria) contributed to hospitalization with influenza at all five coordinating sites. The timing and distribution of viruses varied considerably between the coordinating sites (Figure 2). In Moscow, $\mathrm{A}(\mathrm{H} 1 \mathrm{~N} 1)$ was the most frequent cause of confirmed influenza (53.7\% of cases), peaking at epidemiological week 5 of 2013, followed by an increase in $\mathrm{B}$ and $\mathrm{A}(\mathrm{H} 3 \mathrm{~N} 2)$ towards the end of the season. $\mathrm{A}(\mathrm{H} 1 \mathrm{~N} 1)$ was the most frequent cause of confirmed influenza in Turkey, although results for the full season were not available. In St. Petersburg, $\mathrm{A}(\mathrm{H} 1 \mathrm{~N} 1)$ was a frequent 

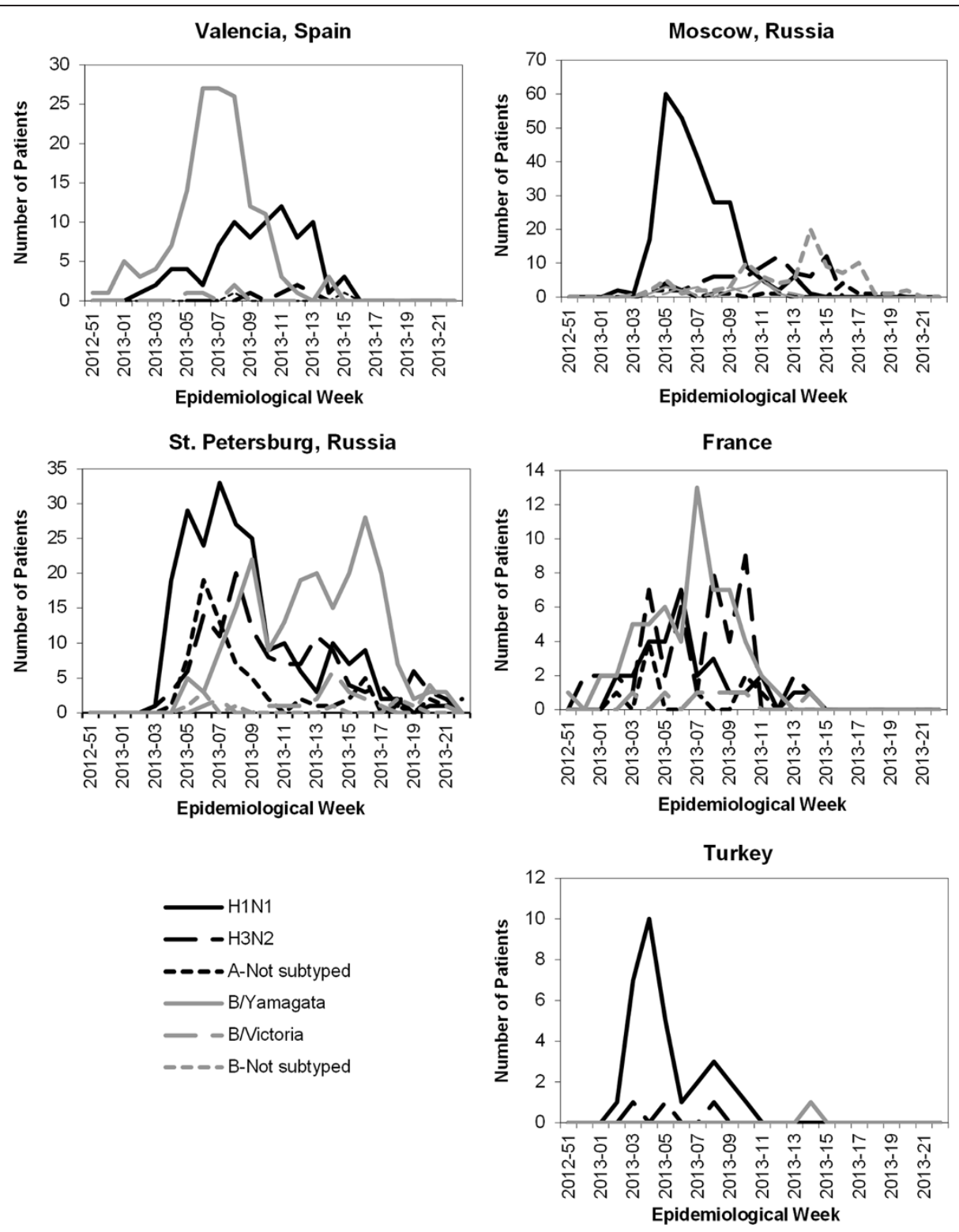

Figure 2 Admissions with influenza by virus and epidemiological week.

cause of confirmed influenza (33.4\%), A(H3N2) (20.2\%) was also common and B lineages (37.9\% overall) appeared later. In Spain, B/Yamagata was the most frequent $(60.6 \%$ overall) and peaked around epidemiological week 6 of 2013, A(H1N1) increased later in the season. In France, the frequency of B virus (44.0\% overall) was slightly higher than of the other influenza viruses, although it cocirculated with the influenza A viruses. Both B virus lineages circulated in all countries. The lineage included in the vaccine (B/Yamagata) was most common, representing $89.2 \%(436 / 489)$ of all $\mathrm{B}$ viruses cases in which the lineage was identified.

At all coordinating sites except for France, A(H1N1) was the most common influenza strain isolated from hospitalized adults 18-64 years of age. In contrast, A (H3N2) and B viruses were more common than A (H1N1) in elderly adults ( $\geq 65$ years of age) at all coordinating sites (Table 4).

\section{Demographics and clinical features of hospitalized} laboratory-confirmed influenza cases

In Spain, France, and Turkey, more than half of influenza cases had one or more comorbidities, whereas at both coordinating sites in the Russian Federation, more than $80 \%$ were reported to have no comorbidities (Table 5). Cardiovascular disease, respiratory disease, and diabetes were the most frequent comorbidities at all coordinating sites among positives for influenza. 
Table 4 Influenza cases detected by coordinating site, virus, and age group

\begin{tabular}{|c|c|c|c|c|c|c|c|c|c|c|c|c|c|c|}
\hline \multirow[b]{2}{*}{ Virus } & \multicolumn{3}{|c|}{ Valencia $(\mathrm{N}=236)$} & \multicolumn{3}{|c|}{ St. Petersburg $(\mathrm{N}=652)$} & \multicolumn{3}{|c|}{ Moscow $(\mathrm{N}=471)$} & \multicolumn{3}{|c|}{ Turkey $(\mathrm{N}=36)$} & \multicolumn{2}{|c|}{ France $(\mathrm{N}=150)$} \\
\hline & $<18 y$ & $18-64$ y & $\geq 65 y$ & $<18 y$ & $18-64$ y & $\geq 65$ y & $<18 y$ & $18-64$ y & $\geq 65 y$ & $<18 y$ & $18-64$ y & $\geq 65 y$ & $18-64 y$ & $\geq 65 y$ \\
\hline Total A & $20(40.0)$ & $29(54.7)$ & $40(30.1)$ & $240(64.0)$ & $171(66.0)$ & $11(61.1)$ & $51(64.6)$ & $284(75.9)$ & $10(55.6)$ & $9(100.0)$ & $17(94.4)$ & $9(100.0)$ & $43(64.2)$ & $43(51.8)$ \\
\hline $\mathrm{A}(\mathrm{H} 1 \mathrm{~N} 1)$ & $19(38.0)$ & $28(52.8)$ & $35(26.3)$ & $113(30.1)$ & $100(38.6)$ & $5(27.8)$ & $30(38.0)$ & $217(58.0)$ & $6(33.3)$ & $9(100.0)$ & $16(88.9)$ & $7(77.8)$ & $20(29.9)$ & $10(12.0)$ \\
\hline $\mathrm{A}(\mathrm{H} 3 \mathrm{~N} 2)$ & $0(0.0)$ & $1(1.9)$ & $4(3.0)$ & 78 (20.8) & $48(18.5)$ & $6(33.3)$ & $18(22.8)$ & $53(14.2)$ & $4(22.2)$ & $0(0.0)$ & $1(5.6)$ & $2(22.2)$ & $18(26.9)$ & $29(34.9)$ \\
\hline A - Not subtyped & $1(2.0)$ & $0(0.0)$ & $1(0.8)$ & $49(13.1)$ & $23(8.8)$ & $0(0.0)$ & $3(3.8)$ & $14(3.7)$ & $0(0.0)$ & $0(0.0)$ & $0(0.0)$ & $0(0.0)$ & $5(7.5)$ & $4(4.8)$ \\
\hline Total B & $30(60.0)$ & $24(45.3)$ & $93(69.9)$ & $144(38.4)$ & $96(37.1)$ & $7(38.9)$ & $28(35.4)$ & $91(24.3)$ & $8(44.4)$ & $0(0.0)$ & $1(5.6)$ & $0(0.0)$ & $26(38.8)$ & $40(48.2)$ \\
\hline B/Yamagata & $28(56.0)$ & $23(43.4)$ & $92(69.2)$ & $127(33.9)$ & $80(30.9)$ & $6(33.3)$ & $6(7.6)$ & $12(3.2)$ & $2(11.1)$ & $0(0.0)$ & $1(5.6)$ & $0(0.0)$ & $20(29.9)$ & $39(47.0)$ \\
\hline B/Nictoria & $2(4.0)$ & $1(1.9)$ & $1(0.8)$ & $10(2.7)$ & $14(5.4)$ & $1(5.6)$ & $2(2.5)$ & $15(4.0)$ & $0(0.0)$ & $0(0.0)$ & $0(0.0)$ & $0(0.0)$ & $6(9.0)$ & $1(1.2)$ \\
\hline B - Not subtyped & $0(0.0)$ & $0(0.0)$ & $0(0.0)$ & $7(1.9)$ & $2(0.8)$ & $0(0.0)$ & $20(25.3)$ & $64(17.1)$ & $6(33.3)$ & $0(0.0)$ & $0(0.0)$ & $0(0.0)$ & $0(0.0)$ & $0(0.0)$ \\
\hline Total & $50(100)$ & $53(100)$ & 133 (100) & 375 (100) & 259 (100) & $18(100)$ & 79 (100) & 374 (100) & $18(100)$ & $9(100)$ & $18(100)$ & $9(100)$ & $67(100)$ & $83(100)$ \\
\hline
\end{tabular}

Values are $n(\%)$. Patients may have had more than one influenza virus due to a mixed infection. 
Table $\mathbf{5}$ Characteristics of subjects hospitalized with laboratory-confirmed influenza

\begin{tabular}{|c|c|c|c|c|c|}
\hline Characteristic & Valencia, Spain & St. Petersburg, Russia & Moscow, Russia & Turkey & France \\
\hline Age & $N=236$ & $N=652$ & $N=471$ & $N=36$ & $N=150$ \\
\hline$<18 y$ & $50(21.2)$ & $375(57.5)$ & $79(16.8)$ & $9(25.0)$ & - \\
\hline $18-64 y$ & $53(22.5)$ & $259(39.7)$ & $374(79.4)$ & $18(50.0)$ & $67(44.7)$ \\
\hline$\geq 65$ y & $133(56.4)$ & $18(2.8)$ & $18(3.8)$ & $9(25.0)$ & $83(55.3)$ \\
\hline Sex & $N=236$ & $N=652$ & $N=471$ & $N=36$ & $N=150$ \\
\hline Male & $124(52.5)$ & $347(53.2)$ & $151(32.1)$ & $22(61.1)$ & $69(46.0)$ \\
\hline Female & $112(47.5)$ & $305(46.8)$ & $320(67.9)$ & $14(38.9)$ & $81(54.0)$ \\
\hline Pregnant $^{a}$ & $1(0.9)$ & $1(0.3)$ & $242(75.6)$ & $1(7.1)$ & $4(4.9)$ \\
\hline Number of comorbidities & $N=236$ & $N=652$ & $N=471$ & $N=36$ & $N=150$ \\
\hline 0 & $97(41.1)$ & $587(90.0)$ & $383(81.3)$ & $8(22.2)$ & $36(24.0)$ \\
\hline 1 & $69(29.2)$ & $46(7.1)$ & $70(14.9)$ & $14(38.9)$ & $52(34.7)$ \\
\hline$\geq 2$ & $70(29.7)$ & $19(2.9)$ & $16(3.4)$ & $14(38.9)$ & $62(41.3)$ \\
\hline Chronic conditions & $N=236$ & $N=652$ & $N=471$ & $N=36$ & $N=150$ \\
\hline Cardiovascular disease & $54(22.9)$ & $48(7.4)$ & $40(8.5)$ & $15(41.7)$ & $49(32.7)$ \\
\hline Respiratory disease & $77(32.7)$ & $17(2.6)$ & $23(4.9)$ & $10(27.8)$ & $61(40.7)$ \\
\hline Diabetes & $56(23.7)$ & $12(1.8)$ & $4(0.9)$ & $7(19.4)$ & $33(22.2)$ \\
\hline Immunodeficiency & $7(3.0)$ & $0(0.0)$ & $0(0.0)$ & $7(19.4)$ & $14(9.3)$ \\
\hline Renal impairment & $18(7.6)$ & $1(0.2)$ & $18(3.8)$ & $5(13.9)$ & $18(12.0)$ \\
\hline Rheumatologic disease & $4(1.7)$ & $0(0.0)$ & $0(0.0)$ & $3(8.3)$ & $17(11.3)$ \\
\hline Neuromuscular disease & $12(5.1)$ & $0(0.0)$ & $4(0.9)$ & $5(13.9)$ & $6(4.0)$ \\
\hline Cirrhosis & $9(3.8)$ & $3(0.5)$ & $10(2.1)$ & $2(5.6)$ & $1(0.7)$ \\
\hline Neoplasm & $5(2.1)$ & $4(0.6)$ & $6(1.3)$ & $8(22.2)$ & $18(12.0)$ \\
\hline Vaccinated 2012-2013 & $N=236$ & $N=652$ & $N=471$ & $N=36$ & $N=150$ \\
\hline Yes & $82(34.8)$ & $11(1.7)$ & $6(1.3)$ & $5(13.9)$ & $50(33.3)$ \\
\hline No & $154(65.3)$ & $641(98.3)$ & $465(98.7)$ & $31(86.1)$ & $100(66.7)$ \\
\hline Outcome & $N=236$ & $N=652$ & $N=471$ & $N=36$ & $N=150$ \\
\hline ICU admission & $4(1.7)$ & $3(0.5)$ & $2(0.4)$ & 11 (30.6) & - \\
\hline Death & $5(2.1)$ & $0(0.0)$ & $0(0.0)$ & $7(19.4)$ & $4(2.7)$ \\
\hline
\end{tabular}

All values are number of subjects with percent in brackets. No data were missing. -, not reported. ${ }^{\mathrm{a} C a l c u l a t e d}$ relative to females.

In Spain and France, more than half of the subjects with influenza were $\geq 65$ years of age, whereas $<5 \%$ in St. Petersburg and Moscow were in this age group. Most of the subjects with influenza in Moscow were 18-64 years of age, while in St. Petersburg, the only site including dedicated paediatric hospitals, most were $<18$ years of age. The male-tofemale ratio for confirmed influenza cases was close to 1 in Spain, St. Petersburg, and France, whereas in Moscow, more women than men were included. Indeed, a maternity ward was included in this site, where 242 pregnant women had influenza. Amongst women 15 to 45 years of age hospitalized for diagnoses possibly related to influenza, pregnancy was significantly associated with a risk of confirmed influenza (adjusted OR, 1.36 [95\% CI, 1.03 - 1.80]).

A total of 16 deaths and 20 intensive care unit admissions were recorded. Outcomes were similar at the different coordinating sites, except for Turkey, which had a disproportionately high number of serious outcomes (11 intensive care unit admissions and 7 deaths). For the 16 deaths, the mean age was 60 years (range, $1-93$ years). Nine of these patients were $>65$ years of age, two had been vaccinated against seasonal influenza during the current season, and seven had more than one comorbidity.

At all five coordinating sites, the length of hospital stay was similar for all influenza circulating viruses (Additional file 3: Figure S1).

\section{Influenza vaccine uptake}

Influenza vaccination coverage among all hospitalized patients included in the study, whether positive or negative for influenza, was low in St. Petersburg (1.4\%), Moscow $(1.7 \%)$, and Turkey (14.5\%) and moderate in Spain (38.9\%) 
and France (47.0\%). Influenza vaccination among all patients was highest in elderly adults in Spain (60.7\%), Turkey (23.1\%), and France (63.8\%). In hospitalized children, regardless RT-PCR results, uptake rates at all coordinating sites were very low $(\leq 5 \%)$.

\section{Discussion}

These results represent the first year's experience from the GIHSN, a prospective hospital-based influenza surveillance network. The data presented are from the 2012-2013 Northern hemisphere influenza season and were collected from 21 hospitals via five coordinating sites in four countries. Of a total of 6033 eligible patients, valid samples were obtained from 5034, of whom 1545 (30.7\%) were positive for influenza.

The study confirmed that influenza can result in serious outcomes not only in elderly people and those with comorbidities but also in the wider population, irrespective of age or sex. It also confirmed that pregnant women are at significant risk for hospitalization with influenza $[19,20]$, which supports global recommendations for prioritizing influenza vaccination for pregnant women [21,22].

The study allowed us to examine the influenza viruses resulting in hospitalization. We found substantial heterogeneity in virus circulation between coordinating sites, even those in neighbouring geographical areas and even within the same site over time. Unexpectedly, influenza B, mostly the Yamagata lineage, was the most common virus identified in elderly adults, where it accounted for more than half of the hospitalized confirmed influenza cases. Thus, as found in a recent structured review [23], influenza B poses a significant health burden. Indeed, influenza $B$ is now receiving increased attention, and quadrivalent influenza vaccines containing both $B$ lineages are now becoming available. Sample sizes were not large enough to examine influenza viral strains according to comorbidities and other risk factors including pregnancy, but this should become possible as the GIHSN grows and sample sizes increase.

Although the patients included in this study were not necessarily representative of the overall population (i.e. subset of hospitalized patients with a diagnosis possibly associated with influenza), vaccination rates in these patients were lower than recommended by the WHO for European countries [24]. The French patients in this study, regardless their RT-PCR result, had the highest vaccination rate at $47.0 \%$, which was similar to the overall rate for France reported in 2010-2011 (50.4\%) [25]. However, it is not unusual to observe some influenza cases in vaccinated individuals because seasonal influenza vaccines have only a moderate protecting effect, especially in elderly adults [26]. The lowest vaccination rates for these patients were in the Russian Federation, where fewer than $2 \%$ reported being vaccinated for seasonal influenza. This may have been due to the peculiarity of the groups enrolled (e.g. mostly pregnant women in Moscow and mostly children in St. Petersburg), poor uptake, the ability of the vaccine to prevent hospitalization, or a combination of these factors, although these influences remain to be assessed over the coming years.

The findings of this study are strengthened by the active surveillance methodology, specific definitions at each site of admission possibly related to an influenza infection, confirmation of influenza cases by RT-PCR, and the consistent body of evidence generated across coordinating sites. In addition, all RT-PCR was carried out by WHO National Influenza Centres (France, Moscow, St. Petersburg, and Turkey) or using the WHO protocol (Spain).

The results should be generally applicable because of the diversity of participating hospitals and healthcare settings. Nevertheless, the adaptation of case identification to the specific local setting, mainly driven by practical considerations, might have increased the sensitivity of the results to geographical variation. For future years, to help reduce heterogeneity between sites, we plan a common standard operating procedure and meetings at the beginning of the study to share pilot data and harmonise criteria and follow-up activities.

\section{Conclusion}

These first-year findings demonstrate that the GIHSN produces relevant, important, and timely data. Despite the size of the network, results were available before the start of the following influenza season. These results will help understand and prepare for seasonal influenza epidemics. In particular, this platform provides annual data on the severe end of the influenza infection spectrum, as represented by hospitalized cases, for a wide range of populations. More formal burden and risk assessment will become available as documentation of the catchment population of these hospitals and wards improves. By adding the ability to evaluate the impact of vaccination programs, these data support those collected by SARI surveillance systems, although the GIHSN employs a broader definition of ILI that encompasses systemic symptoms beyond fever (i.e., malaise, headache, and myalgia).

The breadth of results provided by the GIHSN are particularly useful for assessing the effectiveness and costeffectiveness of intervention programs, and they open the door to further research and public health activities, especially on risk factors and the impact of influenza and influenza vaccination programs in different populations. The approach used by the GIHSN also allows additional components to be added to respond to other scientific questions. During this first year of the GIHSN, only 21 hospitals and four countries were included, but additional hospitals and countries, including some from 
the Southern hemisphere, have already agreed to join the network. Thus, the GIHSN, with its broad regional representativeness and sustainable framework, should continue to contribute significantly to our knowledge of influenza epidemiology.

\section{Additional files}

Additional file 1: Table S1. Admission diagnoses possibly associated with an influenza infection according to the International Classification of Diseases (ICD) versions 9 and 10

\section{Additional file 2: Supplemental methods.}

Additional file 3: Figure S1. Length of hospital stay by coordinating site and influenza strain. Boxes indicate interquartile ranges, bars indicate the upper and lower adjacent values, and points indicate outliers.

\section{Competing interests}

JPB works for the Vaccines Research Area of FISABIO, which has received funding from GlaxoSmithKline, Novartis, Pfizer, Sanofi Pasteur, and Sanofi Pasteur-MSD for conducting studies on infectious disease epidemiology, vaccine effectiveness, pharmacoeconomics, and safety. The Vaccines Research Area is and has been involved in various randomized clinical trials with GlaxoSmithKline, Novartis, Pfizer, and MSD vaccines. AT is a member of a program funded by Sanofi Pasteur. OL has been an investigator on vaccine studies sponsored by and has received travel support to attend scientific meetings from Sanofi Pasteur and other pharmaceutical companies. CM is an employee of Sanofi-Pasteur. All other authors declare no conflicts of interest.

\section{Authors' contributions}

JPB participated in the design of the study; collected, analysed, and interpreted data; participated in preparing the article; and approved the final article. AT, ANS, and ABV participated in the design of the study; analysed and interpreted data; participated in preparing the article; and approved the final article. AS, EB, OL, and MAC participated in the design of the study; collected and interpreted data; participated in preparing the article; and approved the final article. SMU analysed and interpreted data; participated in preparing the article; and approved the final article. CM participated in the design of the study, interpretation of the data; writing of the manuscript; and approved the final article.

\section{Acknowledgments}

The authors thank the staff of the participating hospitals as well as the patients and their families. We would also like to thank Heath Kelly and John Paget for providing useful comments on a previous version of this paper. Medical writing services were provided by Dr. Phillip Leventhal (4Clinics, Paris, France) and were paid for by Sanofi Pasteur.

This study was funded by a public-private partnership agreement between Sanofi Pasteur, the Fundación para el Fomento de la Investigación Sanitaria y Biomédica de la Comunidad Valenciana (FISABIO-Salud Pública), the Research Institute of Influenza, the D.I. Ivanovsky Institute of Virology, the National Influenza Reference Laboratory Capp-Istanbul, and INSERM (Reseau National $d^{\prime}$ Investigation Clinique en Vaccinologie; REIVAC). Sanofi Pasteur participated in the design of the study, interpretation of the data, and writing of the manuscript but did not participate in the conduct of the study or in the collection, management, or analysis of data.

The GIHSN (Global Influenza Hospital Surveillance Network) Group members included: F Aktaş, Ankara, Turkey; G Aydın, Istanbul, Turkey; S Badur, Istanbul, Turkey; A Buigues Vila, Valencia, Spain; S Borekci, Istanbul, Turkey; J Barrenengoa, Castellón, Spain; E ÇakırEdis-Leyla Fındık, Edirne, Turkey; F Carrat, Paris, France; C Carratalá Munuera, Alicante, Spain; M Ciblak, Istanbul, Turkey; M Durusu, Ankara, Turkey; X Duval, Paris, France; F Galtier, Montpellier, France; C. El Guerche-Seblain, Lyon, France; S Gencer, Istanbul, Turkey; V Gil Guillén, Elda, Spain; M Hacımustafaoğlu, Bursa, Turkey; L Kolobukhina, Moscow, Russian Federation; R Larrea González Castellón, Spain; B Lina, Lyon, France; O Launay, Paris, France; R Limón Ramírez, Vila-real, Spain; P Loulergue, Paris France; N Lenzi, Paris, France; C Mahé, Lyon, France; S Martínez-Úbeda, Valencia, Spain; C Merle de
Boever, Montpellier, France; A Natividad Sancho, Valencia, Spain; L Osidak, St. Petersburg, Russian Federation; S Özer, Istanbul, Turkey; M Pisareva, St, Petersburg Russian Federation; D Postil, Limoges, France; J Puig-Barberà, Valencia, Spain; A Şensoy, Istanbul, Turkey; S Şimşek Yavuz, Istanbul, Turkey; A Sominina, St. Petersburg, Russian Federation; K Stolyarov, St. Petersburg, Russian Federation; A Tormos, Valencia, Spain; M Tortajada Girbés, Valencia, Spain; S Trushakova, Moscow, Russian Federation; S Ünal, Ankara, Turkey; P Vanhems, Lyon, France.

\section{Author details}

${ }^{1}$ Fundación para el Fomento de la Investigación Sanitaria y Biomédica de la Comunidad Valenciana (FISABIO-Salud Pública), Valencia, Spain. ${ }^{2}$ Research Institute of Influenza, St. Petersburg, Russian Federation. ${ }^{3}$ D.I. Ivanovsky Institute of Virology, Moscow, Russian Federation. ${ }^{4}$ INSERM, Reseau National $d^{\prime}$ Investigation Clinique en Vaccinologie (REIVAC), Paris, France. ${ }^{5}$ Université Paris Descartes, Sorbonne Paris Cité and Assistance Publique Hôpitaux de Paris, Hôpital Cochin, Paris, France. ${ }^{6}$ National Influenza Reference Laboratory, Istanbul, Turkey. ${ }^{7}$ Sanofi Pasteur, Lyon, France.

Received: 1 April 2014 Accepted: 28 May 2014

Published: 5 June 2014

\section{References}

1. Influenza (Seasonal), factsheet 211. In http://www.who.int/mediacentre/ factsheets/fs211/en/.

2. Paget J, Marquet $\mathrm{R}$, Meijer A, van der Velden K: Influenza activity in Europe during eight seasons (1999-2007): an evaluation of the indicators used to measure activity and an assessment of the timing, length and course of peak activity (spread) across Europe. BMC Infect Dis 2007, 7:141.

3. Thompson WW, Shay DK, Weintraub E, Brammer L, Bridges CB, Cox NJ, Fukuda K: Influenza-associated hospitalizations in the United States. JAMA 2004, 292(11):1333-1340.

4. Thompson WW, Shay DK, Weintraub E, Brammer L, Cox N, Anderson LJ, Fukuda K: Mortality associated with influenza and respiratory syncytial virus in the United States. JAMA 2003, 289(2):179-186.

5. Brammer L, Budd A, Cox N: Seasonal and pandemic influenza surveillance considerations for constructing multicomponent systems. Influenza Other Respir Viruses 2009, 3(2):51-58.

6. Ortiz JR, Sotomayor V, Uez OC, Oliva O, Bettels D, McCarron M, Bresee JS, Mounts AW: Strategy to enhance influenza surveillance worldwide. Emerg Infect Dis 2009, 15(8):1271-1278.

7. World Health Organization: WHO Interim Global Epidemiological Surveillance Standards for Influenza; 2012.

8. Kelly HA, Sullivan SG, Grant KA, Fielding JE: Moderate influenza vaccine effectiveness with variable effectiveness by match between circulating and vaccine strains in Australian adults aged 20-64 years, 2007-2011. Influenza Other Respir Viruses 2013, 7(5):729-737.

9. Ohmit SE, Petrie JG, Malosh RE, Cowling BJ, Thompson MG, Shay DK, Monto AS: Influenza vaccine effectiveness in the community and the household. Clin Infect Dis 2013, 56(10):1363-1369.

10. Public health Agency of Canadian Institutes of Health Research Influenza Research Network (PCIRN): PHAC/CIHR Influenza Research Network 2013 Annual Report; 2013.

11. Skowronski DM, De Serres G, Dickinson J, Petric M, Mak A, Fonseca K, Kwindt TL, Chan T, Bastien N, Charest H, Li Y: Component-specific effectiveness of trivalent influenza vaccine as monitored through a sentinel surveillance network in Canada, 2006-2007. J Infect Dis 2009, 199(2):168-179.

12. Valenciano M, Ciancio B, team IMs: I-MOVE: a European network to measure the effectiveness of influenza vaccines. Euro Surveill 2012, 17:39.

13. Michiels B, Govaerts F, Remmen R, Vermeire E, Coenen S: A systematic review of the evidence on the effectiveness and risks of inactivated influenza vaccines in different target groups. Vaccine 2011, 29(49):9159-9170.

14. Baker M, Kelly H, Wilson N: Pandemic H1N1 influenza lessons from the southern hemisphere. Euro Surveill 2009, 14:42.

15. Beaute J, Broberg E, Plata F, Bonmarin I, OD J, Delgado C, Boddington N, Snacken R: Overrepresentation of influenza $A(H 1 N 1) p d m 09$ virus among severe influenza cases in the 2011/12 season in four European countries. Euro Surveill 2012, 17:9.

16. Poehling KA, Edwards KM, Griffin MR, Szilagyi PG, Staat MA, Iwane MK, Snively BM, Suerken CK, Hall CB, Weinberg GA, Chaves SS, Zhu Y, McNeal 
MM, Bridges CB: The burden of influenza in young children, 2004-2009. Pediatrics 2013, 131(2):207-216.

17. Williamson DA, Huang QS, Roberts SA, Grant CC, MCArthur C, Baker MG: Surveillance for influenza using hospital discharge data may underestimate the burden of influenza-related hospitalization. Infect Control Hosp Epidemiol 2012, 33(10):1064-1066.

18. Influenza case definitions. In http://www.ecdc.europa.eu/en/activities/ surveillance/eisn/surveillance/pages/influenza_case_definitions.aspx.

19. Fiore AE, Uyeki TM, Broder K, Finelli L, Euler GL, Singleton JA, Iskander JK Wortley PM, Shay DK, Bresee JS, Cox NJ, Centres for Disease Control and Prevention (CDC): Prevention and control of influenza with vaccines: recommendations of the Advisory Committee on Immunization Practices (ACIP), 2010. MMWR Recomm Rep 2010, 59(RR-8):1-62.

20. Foppa IM, Haber M, Ferdinands JM, Shay DK: The case test-negative design for studies of the effectiveness of influenza vaccine. Vaccine 2013, 31(30):3104-3109.

21. Healthy People 2020 summary of objectives. In http://healthypeople.gov/ 2020/topicsobjectives2020/pdfs/Immunization.pdf.

22. Strategic Advisory Group of Experts (SAGE) on Immunization. In http:// www.who.int/immunization/sage/en/.

23. Paul Glezen W, Schmier JK, Kuehn CM, Ryan KJ, Oxford J: The burden of influenza B: a structured literature review. Am J Public Health 2013, 103(3):e43-e51.

24. Vaccine European New Integrated Collaboration Effort: Seasonal influenza vaccination survey in EU/EEA, influenza season 2009-10; 2011.

25. Tuppin P, Choukroun S, Samson S, Weill A, Ricordeau P, Allemand H: [Vaccination against seasonal influenza in France in 2010 and 2011: decrease of coverage rates and associated factors]. Presse Med 2012 41(11):e568-e576.

26. Osterholm MT, Kelley NS, Sommer A, Belongia EA: Efficacy and effectiveness of influenza vaccines: a systematic review and metaanalysis. Lancet Infect Dis 2012, 12(1):36-44.

doi:10.1186/1471-2458-14-564

Cite this article as: Puig-Barberà et al:: First-year results of the Global Influenza Hospital Surveillance Network: 2012-2013 Northern hemisphere influenza season. BMC Public Health 2014 14:564.

\section{Submit your next manuscript to BioMed Central and take full advantage of:}

- Convenient online submission

- Thorough peer review

- No space constraints or color figure charges

- Immediate publication on acceptance

- Inclusion in PubMed, CAS, Scopus and Google Scholar

- Research which is freely available for redistribution 